\title{
BMJ Open Atrial fibrillation detection using single lead portable electrocardiographic monitoring: a systematic review and meta-analysis
}

\author{
Satish Ramkumar, ${ }^{1,2,3}$ Nitesh Nerlekar, ${ }^{1,3}$ Daniel D'Souza, ${ }^{3}$ Derek J Pol, ${ }^{3}$ \\ Jonathan M Kalman, ${ }^{4}$ Thomas H Marwick ${ }^{1,2}$
}

To cite: Ramkumar S, Nerlekar N, D'Souza D, et al. Atrial fibrillation detection using single lead portable electrocardiographic monitoring: a systematic review and meta-analysis. BMJ Open 2018;8:e024178. doi:10.1136/ bmjopen-2018-024178

\section{- Prepublication history and} additional material for this paper are available online. To view these files, please visit the journal online (http://dx.doi. org/10.1136/bmjopen-2018024178).

Received 2 June 2018 Revised 13 August 2018 Accepted 17 August 2018

Check for updates

(C) Author(s) (or their employer(s)) 2018. Re-use permitted under CC BY-NC. No commercial re-use. See rights and permissions. Published by BMJ.

${ }^{1}$ Baker Heart and Diabetes Institute, Melbourne, Victoria, Australia

${ }^{2}$ School of Public Health and Preventative Medicine, Monash University, Clayton, Victoria, Australia

${ }^{3}$ Monash Heart, Monash Cardiovascular Research Centre, Melbourne, Victoria, Australia ${ }^{4}$ Department of Cardiology, Royal Melbourne Hospital and the Department of Medicine, University of Melbourne, Melbourne, Victoria, Australia

Correspondence to Dr Thomas H Marwick; tom.marwick@baker.edu.au

\section{ABSTRACT}

Objectives Recent technology advances have allowed for heart rhythm monitoring using single-lead ECG monitoring devices, which can be used for early diagnosis of atrial fibrillation (AF). We sought to investigate the AF detection rate using portable ECG devices compared with Holter monitoring.

Setting, participants and outcome measures We searched the Medline, Embase and Scopus databases (conducted on 8 May 2017) using search terms related to AF screening and included studies with adults aged $>18$ years using portable ECG devices or Holter monitoring for AF detection. We excluded studies using implantable Ioop recorders and pacemakers. Using a random-effects model we calculated the overall AF detection rate. Metaregression analysis was performed to explore potential sources for heterogeneity. Quality of reporting was assessed using the tool developed by Downs and Black. Results Portable ECG monitoring was used in 18 studies $(n=117436)$ and Holter monitoring was used in 36 studies $(n=8498)$. The AF detection rate using portable ECG monitoring was $1.7 \%$ (95\% $\mathrm{Cl} 1.4$ to 2.1$)$, with significant heterogeneity between studies $(p<0.001)$. There was a moderate linear relationship between total monitoring time and AF detection rate ( $r=0.65, p=0.003)$, and metaregression identified total monitoring time $(p=0.005)$ and body mass index $(\mathrm{p}=0.01)$ as potential contributors to heterogeneity. The detection rate $(4.8 \%, 95 \% \mathrm{Cl} 3.6 \%$ to $6.0 \%$ ) in eight studies ( $n=10199)$, which performed multiple ECG recordings was comparable to that with 24 hours Holter $(4.6 \%, 95 \% \mathrm{Cl} 3.5 \%$ to $5.7 \%)$. Intermittent recordings for $19 \mathrm{~min}$ total produced similar $\mathrm{AF}$ detection to 24 hours Holter monitoring.

Conclusion Portable ECG devices may offer an efficient screening option for AF compared with 24 hours Holter monitoring.

PROSPERO registration number CRD42017061021.

Atrial fibrillation (AF) is a leading cause of stroke and heart failure worldwide, and is associated with increased all-cause mortality ${ }^{12}$ as well as substantial financial cost. ${ }^{34}$ The prevalence of AF increases with age, exceeding $>15 \%$ for those aged 85 years and older. ${ }^{5}$ The epidemics of obesity, diabetes mellitus and
Strengths and limitations of this study

- First systematic review comparing single-lead ECG monitoring with 24 hours Holter monitoring for atrial fibrillation (AF) detection.

- Comprehensive literature search and specific inclusion criteria allowing for large patient numbers.

- Heterogeneity among individual studies with regard to patient population, AF definitions and monitoring time.

- Poor reporting of $\mathrm{CHA}_{2} \mathrm{DS}_{2}$-VASC scores among individual studies.

- Patient compliance unable to be accounted for in this meta-analysis.

metabolic syndrome have also been associated with the increasing prevalence of $\mathrm{AF}^{6-8}$ Up to $20 \%$ of patients with stroke have underlying $\mathrm{AF}$, and detection allows the initiation of anticoagulation, which is associated with a significant reduction in stroke recurrence. ${ }^{9}$

Early diagnosis of AF may have several benefits, including individualised lifestyle intervention ${ }^{10}$ and anticoagulation, and may be associated with a reduction in complications and healthcare costs. The importance of early diagnosis has been recognised in recent guidelines from the European Society of Cardiology, which recommended opportunistic screening using pulse palpation and 12-lead ECG. ${ }^{11}$ However, screening for $\mathrm{AF}$ is challenging for several reasons; many patients are asymptomatic or may have atypical symptoms. There are a variety of monitoring techniques available, all of which vary in diagnostic accuracy and sensitivity, and there is no accepted reference standard. Subclinical AF is associated with an increased risk of stroke, cardiovascular disease and all-cause mortality, ${ }^{12}$ although there is controversy surrounding the significance of brief paroxysms of $\mathrm{AF}$ and the potential benefit of 
anticoagulant therapy. Implantable devices are expensive, and not cost-effective for mass screening, and the use of external devices for long periods of monitoring require electrodes, which may be poorly tolerated by patients.

Recent advances in technology have allowed for the development of single-lead portable ECG monitoring devices. Multiple devices are available, all using multiple points of finger contact to create a single-lead ECG trace. The in-built memory of these devices allows for single or multiple time-point screening. Interpretation from a cardiologist or by automated algorithms has achieved high sensitivity and specificity for AF detection. ${ }^{13-15}$ Although they have not been incorporated into the latest $\mathrm{AF}$ guidelines, the accuracy, ease of use and potential cost-effectiveness of these devices may lead to them having an important role in AF screening. This paper describes a systematic review of the published literature to investigate the overall AF detection rate using portable ECG devices compared with traditional Holter monitoring.

\section{METHODS}

\section{Search strategy}

We conducted our systematic review and meta-analysis using the Preferred Reporting Items for Systematic Reviews and Meta-Analyses guideline (PRISMA). ${ }^{16}$ We searched the Medline, Scopus and Embase databases using key terms including 'atrial fibrillation/AF and screening/monitoring and electrocardiographic/Holter monitoring', which were mapped to subject headings. We also searched the reference lists to identify other potential articles. The search was limited to adult human subjects aged $>18$ years and limited to the English language (see search strategy for Medline database in online supplementary material 1 ). The study was prospectively registered on the PROSPERO database on 22 April 2017 (CRD42017061021), and the search was conducted on 8 May 2017.

\section{Study selection}

Titles and abstracts of studies identified from the search were reviewed by two independent reviewers (SR and DDS). Studies which had a primary aim of AF detection in adult participants were included. We included all cohorts including community screening, those with risk factors and recent stroke. The screening methods included portable single-lead ECG devices or continuous (Holter) monitoring (up to 1 week). We included studies which used single-lead ECG devices for single episode screening or multiple intermittent screening periods. We included conference abstracts if demographic and outcome data were available. We excluded studies if participants were aged $<18$ years or if other forms of monitoring were used (pacemaker, implantable loop recorders, event recorders, monitoring patches and inpatient telemetry). We also excluded studies where AF detection was not the primary aim.
The primary outcome of interest was the detection rate of new AF using either single-lead intermittent or continuous monitoring. Our secondary objective was to determine the optimal time of intermittent monitoring, which produced equivalent $\mathrm{AF}$ detection to continuous monitoring.

\section{Data collection}

Full-text manuscripts of studies fitting the inclusion criteria were obtained. Quality of reporting and risk of bias was assessed using the tool developed by Downs and Black. ${ }^{17}$ A standardised data-extraction form was used by the reviewers, which included information about the patient demographics, comorbidities, screening strategy, patients with known $\mathrm{AF}$ and overall new $\mathrm{AF}$ detection rate. Where data were not reported, we attempted to contact the primary authors of the study. Any disagreements between the two reviewers were resolved by consensus or by consulting a third reviewer (THM).

\section{Statistical analysis}

The cumulative AF detection rate for continuous and intermittent monitoring and the 95\% CI was calculated using a random-effects model. The results were displayed as a forest plot and heterogeneity among the studies was assessed using the $\mathrm{I}^{2}$ statistic. A subgroup analysis was performed by comparing the cumulative detection rate of single-lead ECG studies, which performed multiple timepoint recordings with 24 hours Holter monitoring studies. Linear regression analysis was used to determine the association between the total monitoring time and AF detection using single-lead ECG devices. This formula was used to determine the monitoring time using singlelead ECG devices to approximate the overall AF detection rate using 24 hours continuous monitoring. Univariate meta-regression analysis was performed to assess the influence of various clinical and screening factors with AF detection. Publication bias was assessed using a funnel plot and the Egger test. Statistical analysis was performed using Stata V.13 (StataCorp, College Station, Texas, USA) with two-tailed $\mathrm{p}$ values $<0.05$ used to denote statistical significance.

\section{Patient and public involvement}

Patients were not involved in this review.

\section{RESULTS}

\section{Study characteristics}

The PRISMA flow chart of our included studies is shown in figure 1 and the search strategy in online supplementary table 1. Our initial search strategy identified 5427 studies, with another 26 identified through other sources. After removing duplicate records, 4122 studies were left. After screening those using the inclusion/exclusion criteria, we identified 111 full-text studies for detailed review, which excluded 59 studies, leaving 52 full-text studies for inclusion in the meta-analysis (see online supplementary 


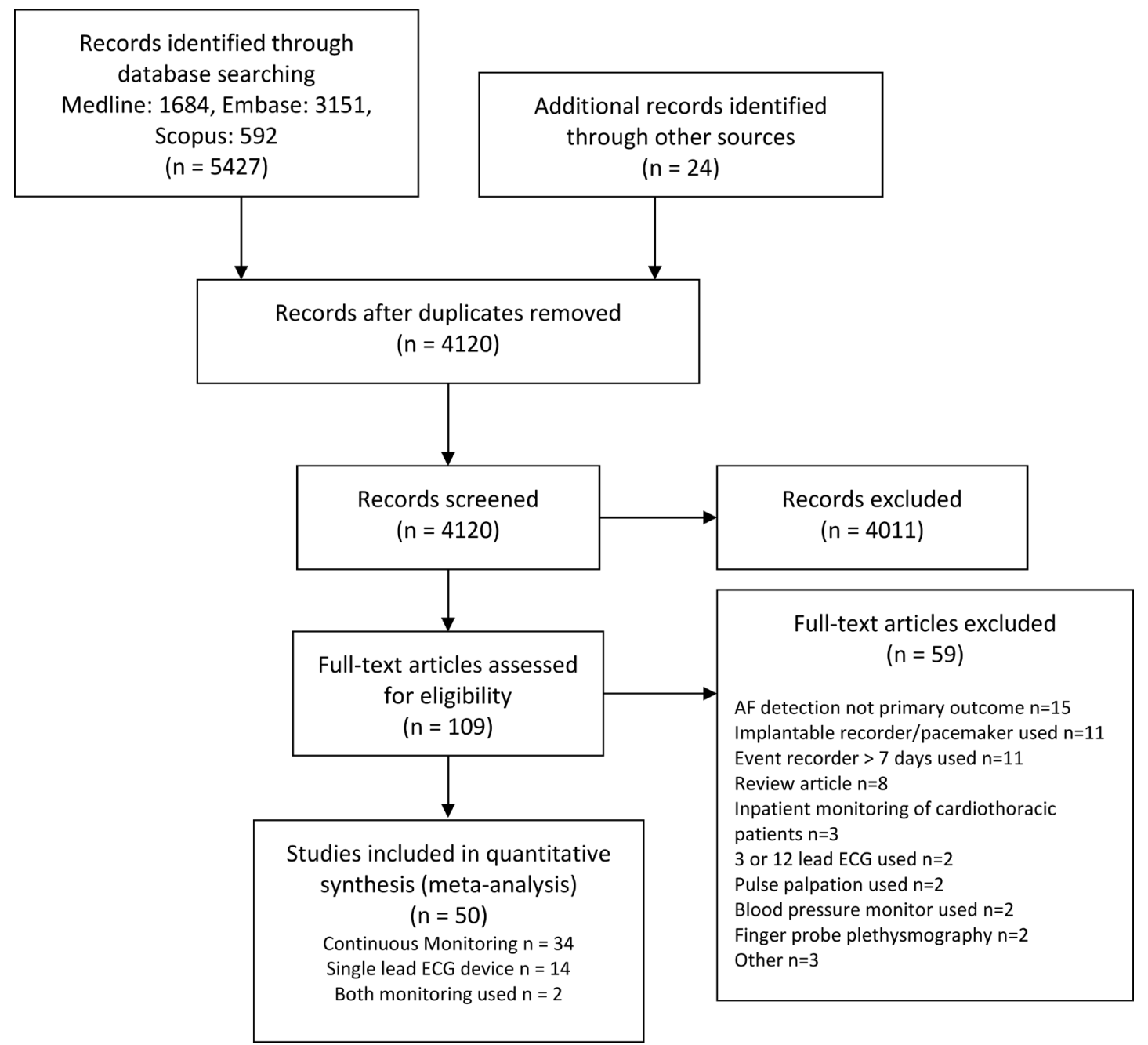

Figure 1 Overview of inclusion and exclusion of studies based on the Preferred Reporting Items for Systematic Reviews and Meta-Analyses flow chart.

table 2 for excluded studies). Of the 52 studies included, 34 used continuous (Holter) monitoring $(\mathrm{n}=8154))^{18-51}$ 16 studies $(n=117092)$ used single-lead portable ECG monitoring $^{14} 15{ }^{52-65}$ and 2 studies $(n=344)$ used both continuous and intermittent single-lead monitoring for AF detection in a head-to-head comparison. ${ }^{6667}$

The baseline characteristics of the individual studies is presented in table 1 . There was a considerable range in age (54-76 years), and gender (male 29\%-77\%) between studies. As many studies chose healthy volunteers and other studies focused on patients poststroke or those with $\mathrm{AF}$ risk factors, there was significant variation in comorbidities such as diabetes, hypertension and obesity. Stroke risk determined by the CHADS or $\mathrm{CHA}_{2} \mathrm{DS}_{2}$-VASC score was reported in only $14 / 52$ studies $(27 \%)$. Of the 52 studies, $36(69 \%)$ were conducted in Europe, $8(15 \%)$ in Asia, $5(10 \%)$ in North America and $3(6 \%)$ in Australia. Nine studies $(17 \%)$ were retrospective, the remainder all being prospective cohort or randomised controlled trials.

Of the 18 studies using single-lead ECG devices, 10 studies $(56 \%)$ used a single $10-60 \mathrm{~s}$ recording for $\mathrm{AF}$ detection while 8 studies $(44 \%)$ used multiple readings over a 1 -week to 52 -week period. There were five portable
ECG devices used (table 1). Sixteen studies (89\%) used healthy participants with risk factors. 1415 52-61 63-65 67 Two studies assessed patients following stroke or transient ischaemic attack (TIA). ${ }^{62} 66$

Of the 36 studies using continuous (Holter) monitoring, 27 studies $(75 \%)$ used 24 hours continuous monitoring, ${ }^{18-23} \quad 25-28 \quad 33-36 \quad 38 \quad 39 \quad 41-45 \quad 47-50 \quad 66 \quad 674$ studies $(11 \%)$ used 1-week monitoring, ${ }^{30-32} 512$ studies $(6 \%)$ used 48 hours monitoring, ${ }^{37}{ }^{46} 2$ studies (6\%) used 72 hours monitoring ${ }^{24} 29$ and 1 study (3\%) used 96 hours monitoring. ${ }^{40}$

\section{Overall AF detection}

The combined AF detection rate using single-lead ECG monitoring ( $\mathrm{n}=117436$ from 18 studies) was $1.7 \%(95 \%$ CI $1.4 \%$ to $2.1 \%)$. The cumulative $\mathrm{AF}$ detection rate using continuous (Holter) monitoring ( $\mathrm{n}=8498$ from 36 studies) was $5.5 \%$ (95\% CI $4.4 \%$ to $6.6 \%)$. There was significant heterogeneity between studies $\left(\mathrm{I}^{2}=94 \%\right.$ for single-lead ECG monitoring, $87 \%$ for Holter monitoring). The overall new AF detection rate is presented in figure 2. 


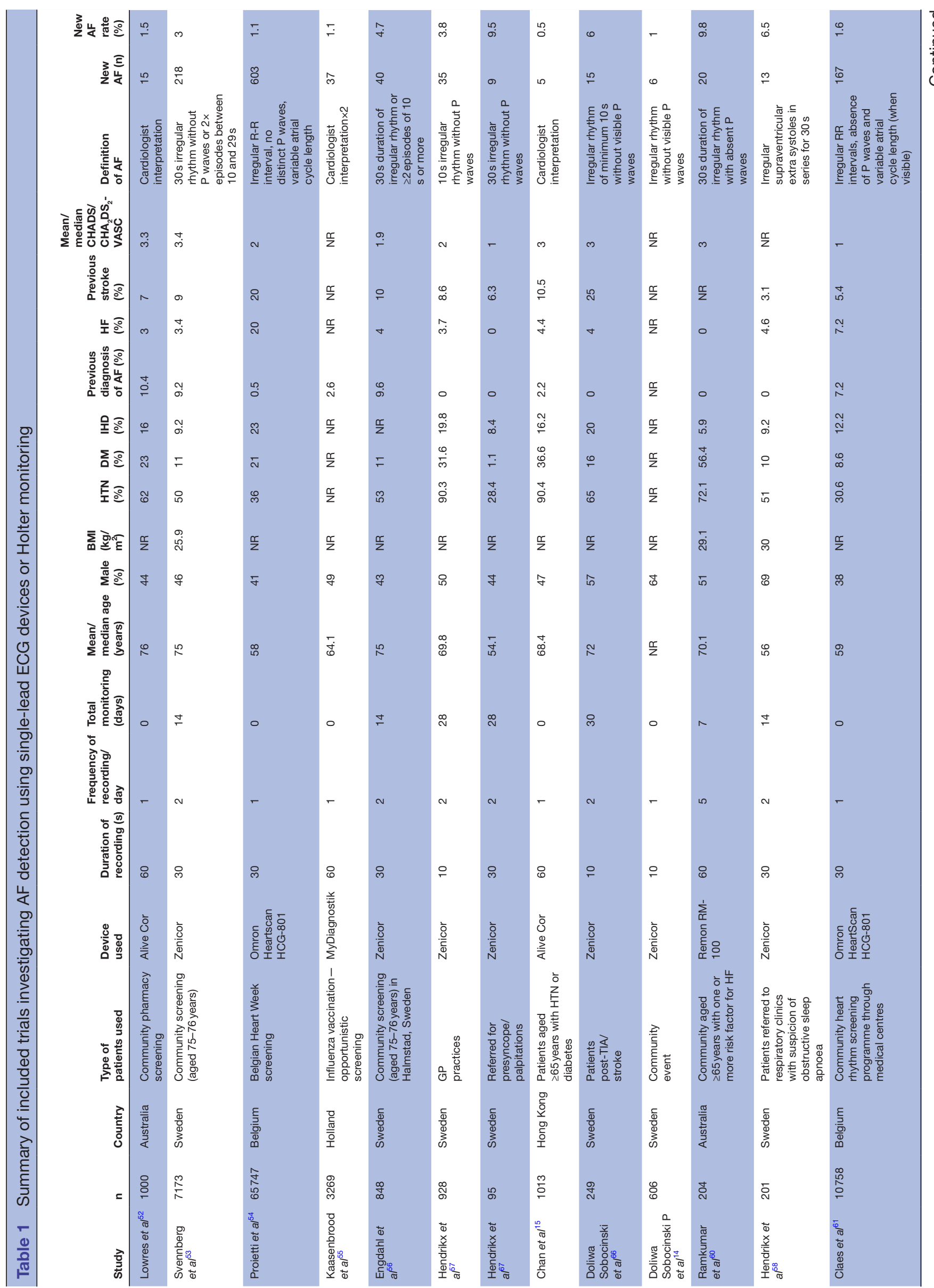




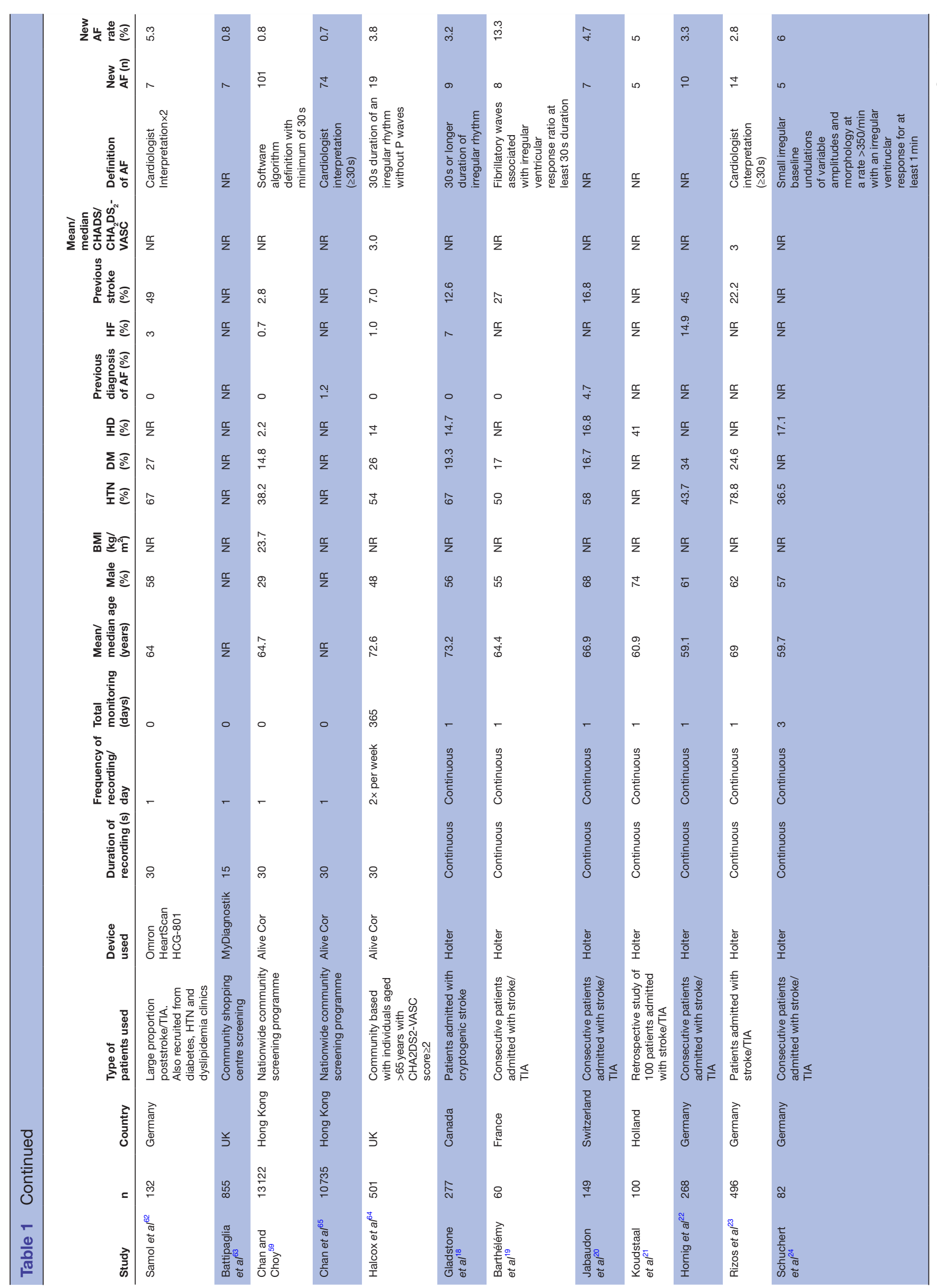




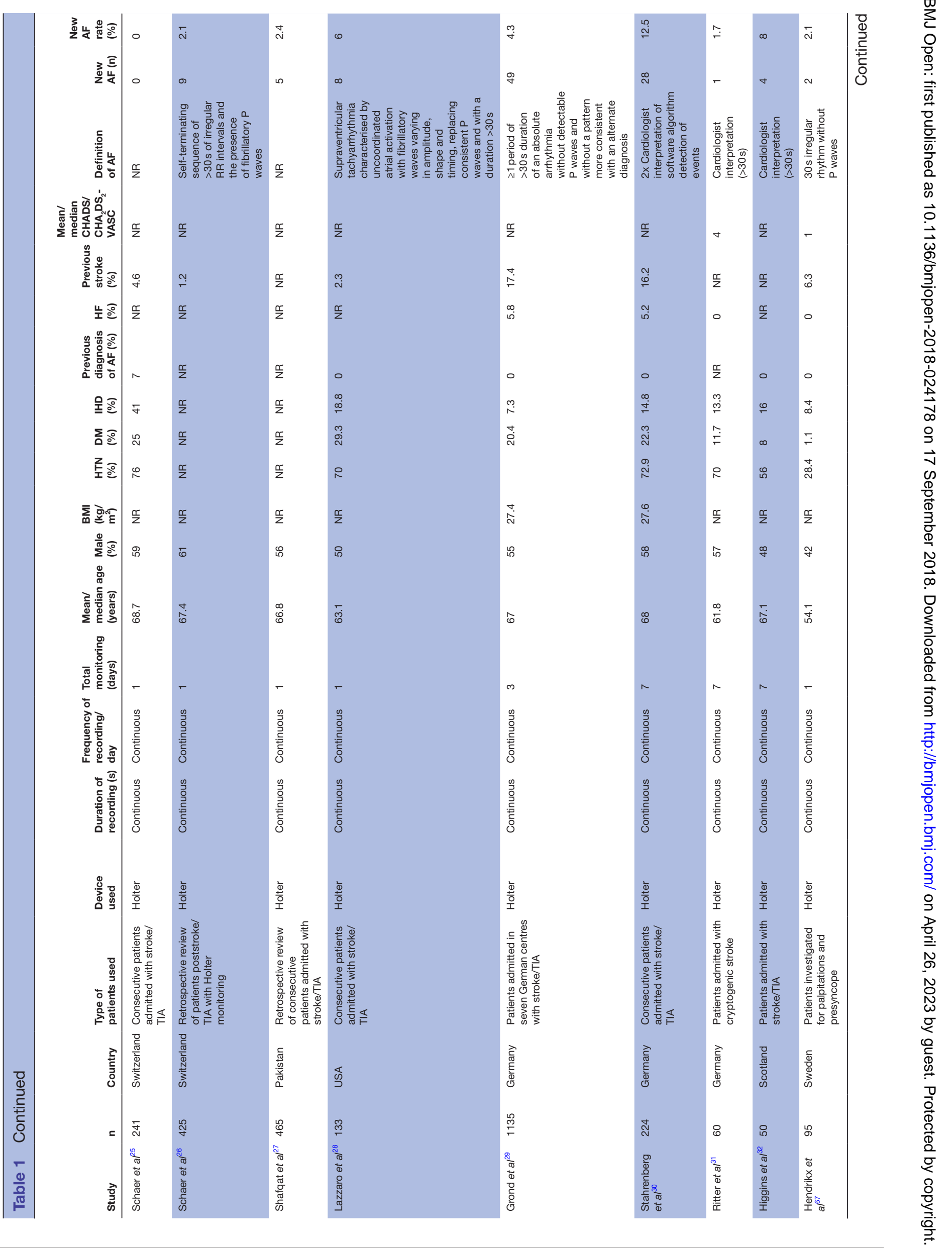




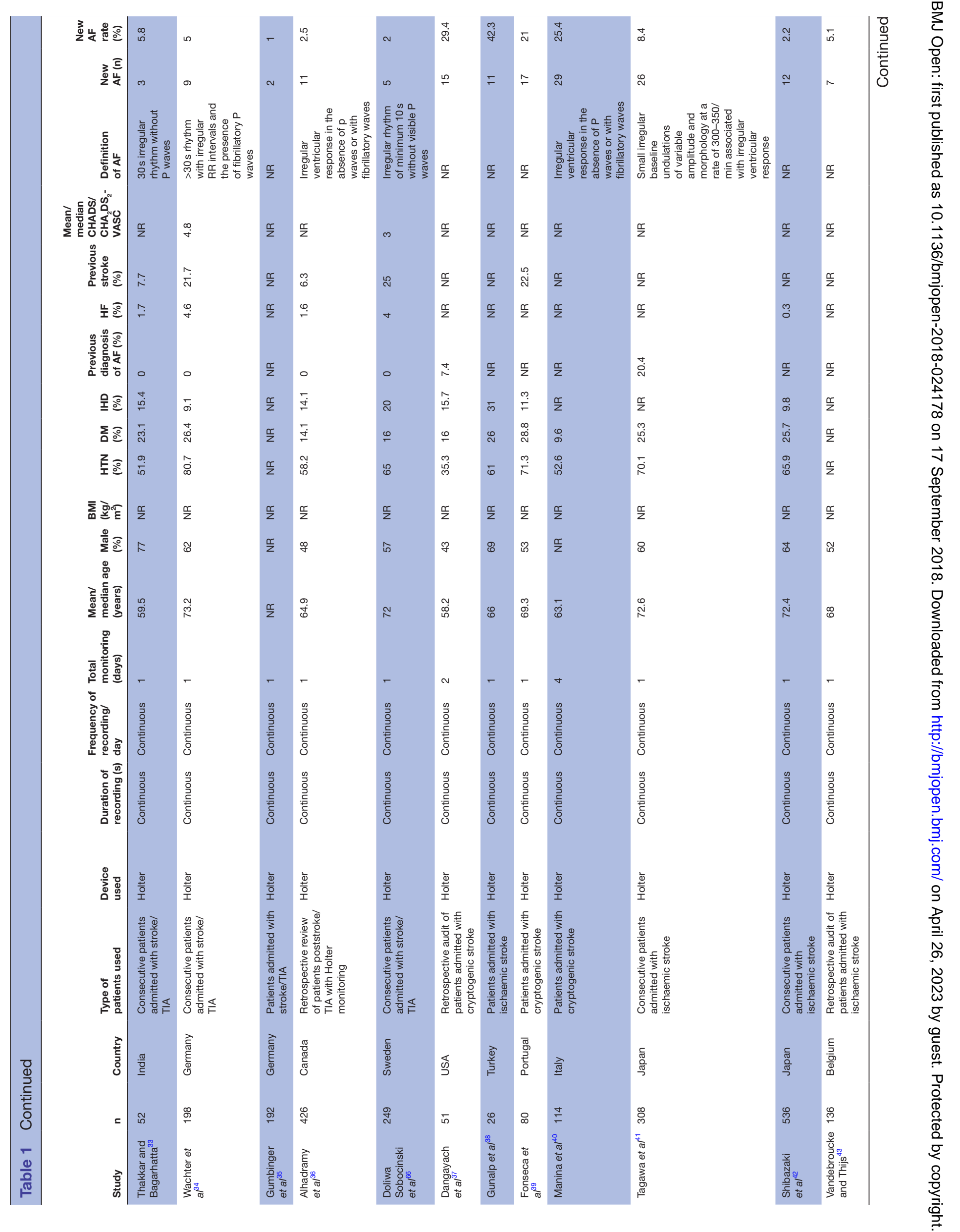




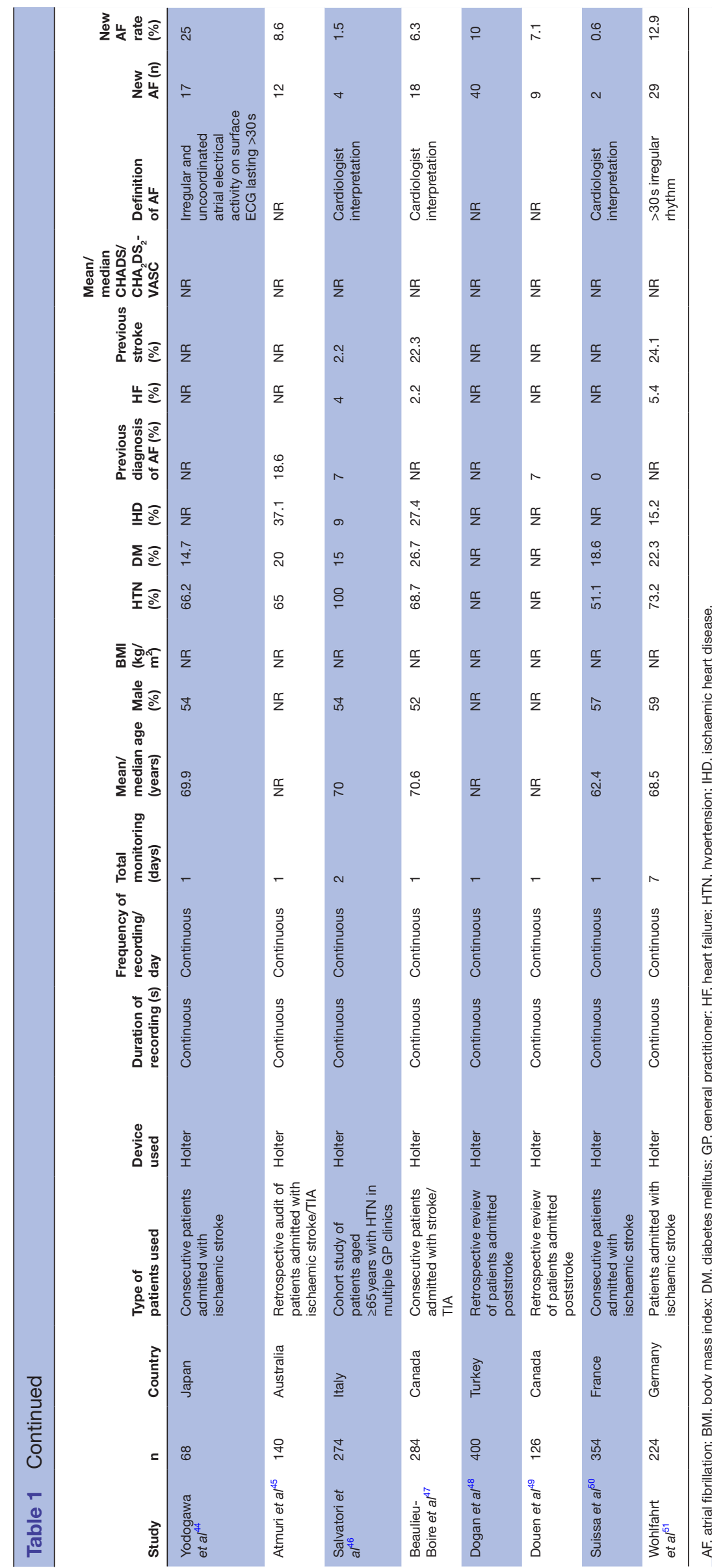

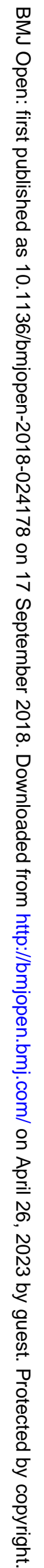




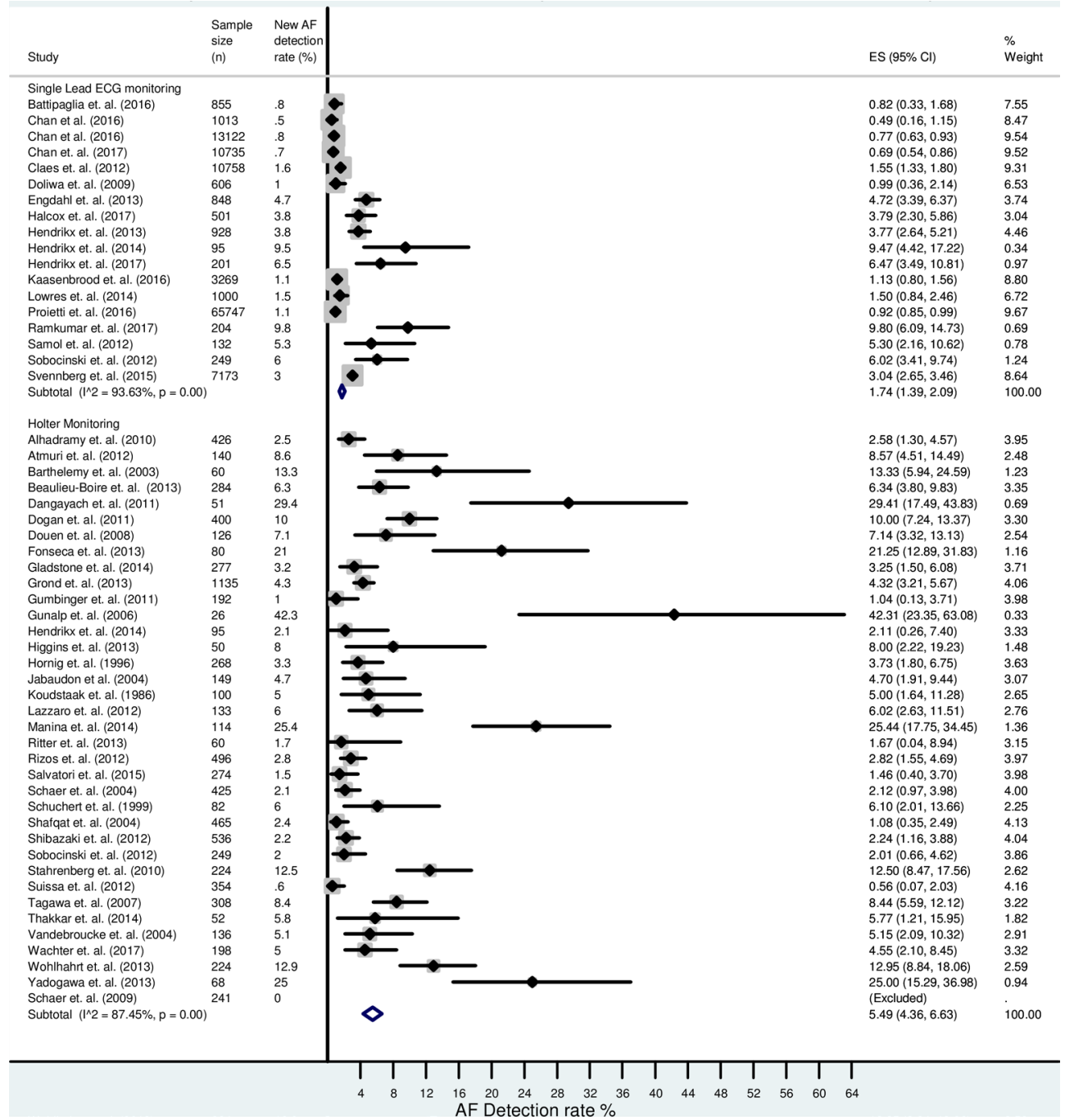

Figure 2 Forest plot showing the overall atrial fibrillation (AF) detection rate between single-lead ECG devices and Holter monitoring.

\section{Comparison of multiple intermittent monitoring with 24 hours Holter}

There was significant variation in the monitoring time using both single-lead and Holter monitoring, which contributed to the difference in the cumulative detection rate seen in figure 2. Figure 3 compares the detection rate of multiple intermittent single-lead recordings with 24 hours continuous monitoring, which is used routinely in clinical practice. There were eight studies $(\mathrm{n}=10199$, mean weighted age $68.8 \pm 8.4$ years from six studies, $47 \%$ male from eight studies) that performed multiple intermittent single-lead ECG recordings and 27 studies $(\mathrm{n}=6284$, mean weighted age $67.8 \pm 5.1$ years from 23 studies, $58 \%$ male from 23 studies) that used 24 hours Holter monitoring. From the data available, the multiple intermittent ECG group had a lower AF risk to the 24 hours Holter group (hypertension $55 \%$ ( $\mathrm{n}=8$ studies) vs $65 \%$ ( $\mathrm{n}=20$ studies); diabetes mellitus $15 \%$ ( $\mathrm{n}=8$ studies) vs $22 \%$ ( $\mathrm{n}=20$ studies); heart failure $3.3 \%$ ( $\mathrm{n}=8$ studies) vs $3.9 \%$ ( $n=11$ studies); ischaemic heart disease $11 \% \quad(n=6$ studies) vs $19 \%$ ( $\mathrm{n}=15$ studies) and previous stroke/TIA
$9 \%$ ( $\mathrm{n}=7$ studies ) vs $16 \%$ ( $\mathrm{n}=15$ studies $)$ ), respectively. The combined AF detection rate was 4.8\% (95\% CI 3.6\% to $6.0 \%$ ) using multiple intermittent ECG recordings. The cumulative AF detection rate using 24 hours Holter monitoring was $4.6 \%$ (95\% CI $3.5 \%$ to $5.7 \%$ ).

\section{Association between monitoring time and AF detection}

Using single-lead ECG devices, we found a moderate linear relationship between the total monitoring time and AF detection rate $\left(\beta=0.13, R^{2}=0.42\right)$. Using this formula, we noted that approximately $19 \mathrm{~min}$ of total intermittent monitoring produced similar AF detection to 24 hours continuous monitoring (figure 4). The study by Halcox et al was an outlier, with a much lower $\mathrm{AF}$ detection rate than other studies $(3.8 \%$ from $52 \mathrm{~min}$ of total monitoring) and this reduced the linear correlation between total monitoring time and $\mathrm{AF}$ detection rate. ${ }^{64}$ Exclusion of these data led to a stronger linear relationship $(\beta=0.26$, $\mathrm{R}^{2}=0.80$ ) and a much lower total intermittent monitoring time required (12 $\mathrm{min})$ to produce a similar $\mathrm{AF}$ detection rate to 24 hours Holter monitoring. 


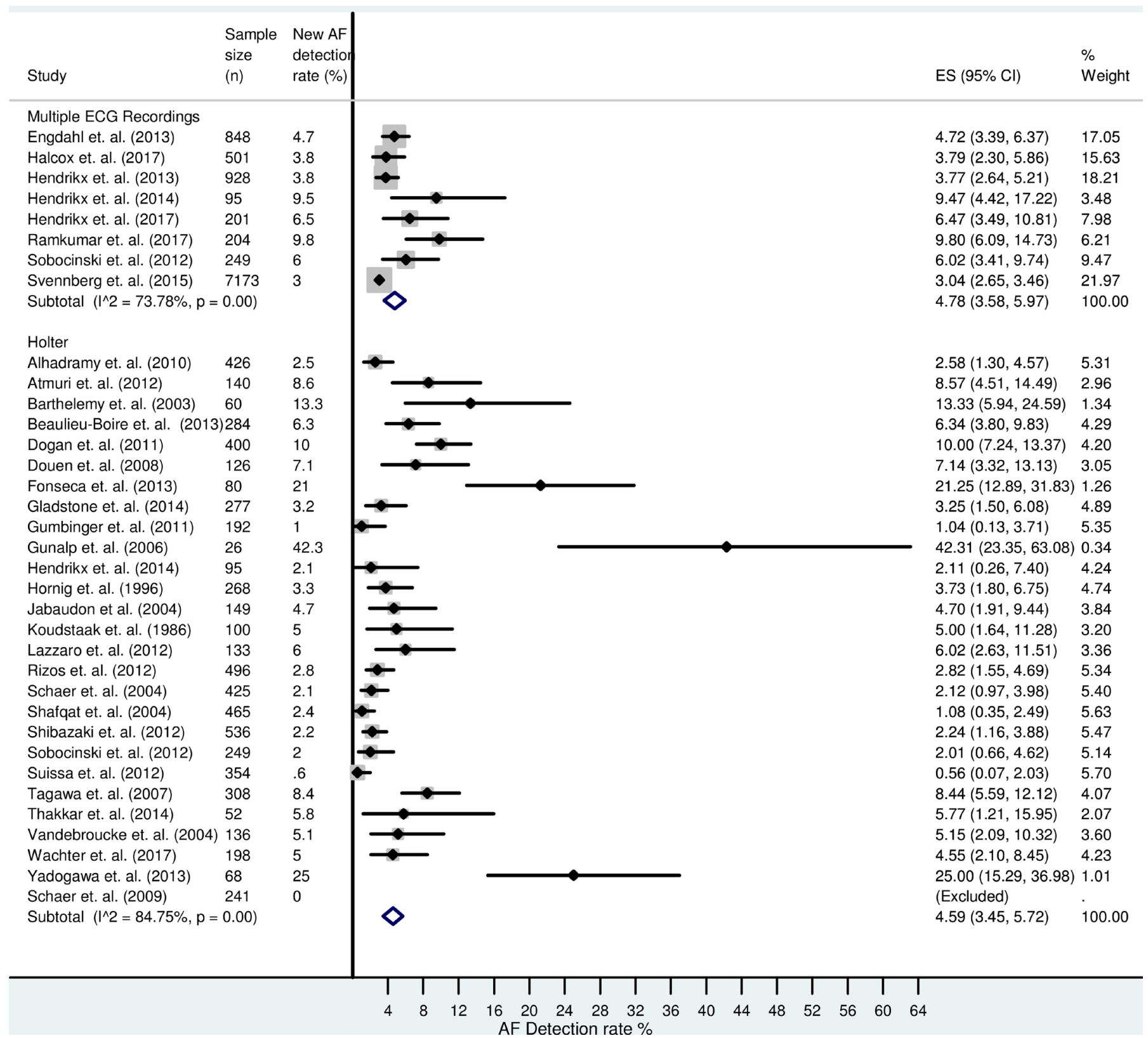

Figure 3 Forest plot comparing the atrial fibrillation (AF) detection rate between 24 hours Holter monitoring and performing multiple intermittent single-lead ECG recordings.

\section{Meta-regression}

Sources of heterogeneity in the 18 studies using singlelead ECG monitoring were investigated using meta-regression (table 2). Monitoring time per participant $(\beta=0.11,95 \%$ CI 0.04 to $0.18, p=0.005)$ and body mass index ( $\beta=1.1,95 \%$ CI 0.58 to $1.5, p=0.01$ ) were associated with $\mathrm{AF}$ detection.

\section{Sensitivity analysis}

A number of outlier studies were observed in the meta-analysis that could influence the cumulative AF detection rate. ${ }^{37-40} 44$ Removal of these outlier studies resulted in a reduction in the overall $\mathrm{AF}$ detection rate in all Holter studies (table 3 ) and for 24 hours Holter studies (table 4 ). When these outlier studies were removed, the overall $\mathrm{AF}$ detection rate for 24 hours Holter was $3.86 \%$ (95\% CI $2.88 \%$ to $4.83 \%$ ), much lower than the detection rate by multiple intermittent ECG recordings using portable single lead devices $(4.78 \%, 95 \%$ CI $3.58 \%$ to $5.97 \%$ ). A cumulative meta-analysis (figure 5) did not show any significant variation in the AF detection rate over time using either Holter or single-lead ECG monitoring.

\section{Publication bias}

Publication bias was explored using a funnel plot of all included studies (see online supplementary figure 1). There was significant publication bias in both single-lead ECG device and Holter monitoring studies (Egger test, $\mathrm{p}=0.003$ and $\mathrm{p}<0.001$ respectively). 


\section{AF Detection using portable ECG devices based on monitoring time per patient}

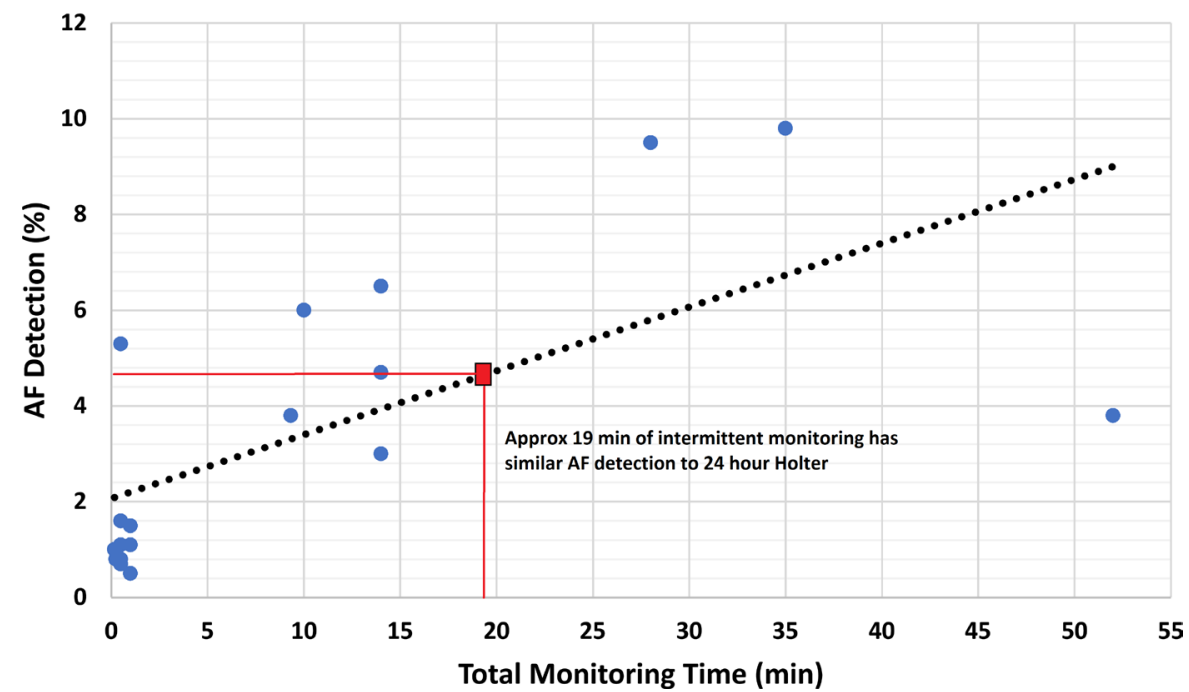

Figure 4 Graph showing the linear relationship between total monitoring time and atrial fibrillation (AF) detection rate in singlelead ECG devices.

\section{Quality of studies}

A summary of the quality analysis (see online supplementary table 3 ) showed that overall quality of reporting was moderate. All studies described the primary objective of the trial and included a summary of the main findings. Detailed comorbidities of the study participants were only adequately reported in 28/52 (54\%), and limitations were discussed in 35/52 $(67 \%)$ of studies. Most had a very selective patient population, $31 / 52(60 \%)$ were poststroke/TIA cohorts.

\section{DISCUSSION}

Our study is the only systematic review that we are aware of that has studied the overall AF detection rate of singlelead portable ECG devices. The results of our systematic

\begin{tabular}{|c|c|c|c|}
\hline Variable & $\begin{array}{l}\text { Number of } \\
\text { studies }\end{array}$ & $\beta(95 \% \mathrm{Cl})$ & $P$ values \\
\hline Age (years) & 15 & $0.00(-0.22$ to 0.24$)$ & 0.95 \\
\hline $\begin{array}{l}\text { Monitoring time per } \\
\text { participant (min) }\end{array}$ & 18 & 0.11 (0.04 to 0.18$)$ & 0.005 \\
\hline $\begin{array}{l}\text { Body mass index } \\
\left(\mathrm{kg} / \mathrm{m}^{2}\right)\end{array}$ & 4 & $1.1(0.58$ to 1.5$)$ & 0.01 \\
\hline CHADS score (\%) & 11 & $-0.13(-2.6$ to 2.4$)$ & 0.91 \\
\hline Hypertension (\%) & 14 & $0.01(-0.08$ to 0.10$)$ & 0.75 \\
\hline $\begin{array}{l}\text { Previous diagnosis } \\
\text { of } \mathrm{AF}(\%)\end{array}$ & 16 & $-0.13(-0.50$ to 0.24$)$ & 0.46 \\
\hline $\begin{array}{l}\text { Ischaemic heart } \\
\text { disease (\%) }\end{array}$ & 12 & $-0.10(-0.42$ to 0.21$)$ & 0.48 \\
\hline Previous stroke (\%) & 13 & $0.06(-0.09$ to 0.19$)$ & 0.45 \\
\hline Male gender & 16 & $0.10(-0.04$ to 0.24$)$ & 0.16 \\
\hline
\end{tabular}

review suggest a linear relationship between monitoring time per patient and AF detection rate. Single timepoint screening has an approximate $1 \% \mathrm{AF}$ detection rate, which can be increased to around $5 \%$ when multiple recordings are performed. We noted that approximately $19 \mathrm{~min}$ of intermittent monitoring produced similar detection rates to conventional 24 hours continuous Holter monitoring.

\section{Early diagnosis of AF}

AF creates a significant burden on both patients as well as the healthcare system. AF will continue to rise in incidence and the costs to the healthcare system will continue to increase, due to ageing, sedentariness and the prevalence of obesity and the metabolic syndrome. ${ }^{368}$ Early diagnosis offers the possibility for early initiation of treatment, which may reduce the occurrence of the complications and may lead to reduced hospital admissions and associated healthcare costs. Early treatment for AF can be achieved in different ways. Patients with subclinical $\mathrm{AF}$ have an increased risk of stroke and cardiovascular

Table 3 Outlier studies omitted (all Holter studies) to assess the change to the overall atrial fibrillation (AF) detection rate

\begin{tabular}{lll}
\hline Study omitted & $\begin{array}{l}\text { Overall AF } \\
\text { detection rate (\%) }\end{array}$ & $\mathbf{9 5 \%} \mathbf{C l ~ ( \% )}$ \\
\hline Dangayach et $\left.a\right|^{37}$ & 5.27 & 4.17 to 6.38 \\
\hline Fonseca et $\left.a\right|^{39}$ & 5.26 & 4.15 to 6.36 \\
\hline Gunalp et $a l^{38}$ & 5.32 & 4.21 to 6.42 \\
\hline Manina et $a l^{40}$ & 5.11 & 4.03 to 6.20 \\
\hline Yadogawa et al ${ }^{44}$ & 5.25 & 4.14 to 6.35 \\
\hline All studies excluded & 4.31 & 3.36 to 5.26 \\
\hline
\end{tabular}


Table 4 Outlier studies omitted ( 24 hours Holter) to assess the change to the overall atrial fibrillation (AF) detection rate

\begin{tabular}{lll}
\hline Study omitted & $\begin{array}{l}\text { Overall AF } \\
\text { detection rate (\%) }\end{array}$ & $\mathbf{9 5 \%} \mathbf{C l}(\%)$ \\
\hline Fonseca et $\left.a\right|^{39}$ & 4.30 & 3.21 to 5.39 \\
\hline Gunalp et $\left.a\right|^{38}$ & 4.39 & 3.30 to 5.47 \\
${\text { Yadogawa et } a l^{44}}_{\text {All studies excluded }}$ & 4.30 & 3.22 to 5.38 \\
\hline
\end{tabular}

events, like those with established AF. ${ }^{1269}$ Anticoagulation may help reduce the incidence of stroke in this cohort.

The close relationship between metabolic syndrome and $\mathrm{AF}$ has encouraged research into the benefits of lifestyle intervention. Aggressive lifestyle intervention in patients with AF undergoing catheter ablation has been reported to lead to a reduction in symptom burden, improved quality of life and the need for repeat ablation procedures. ${ }^{10}$ It remains to be tested whether initiation of

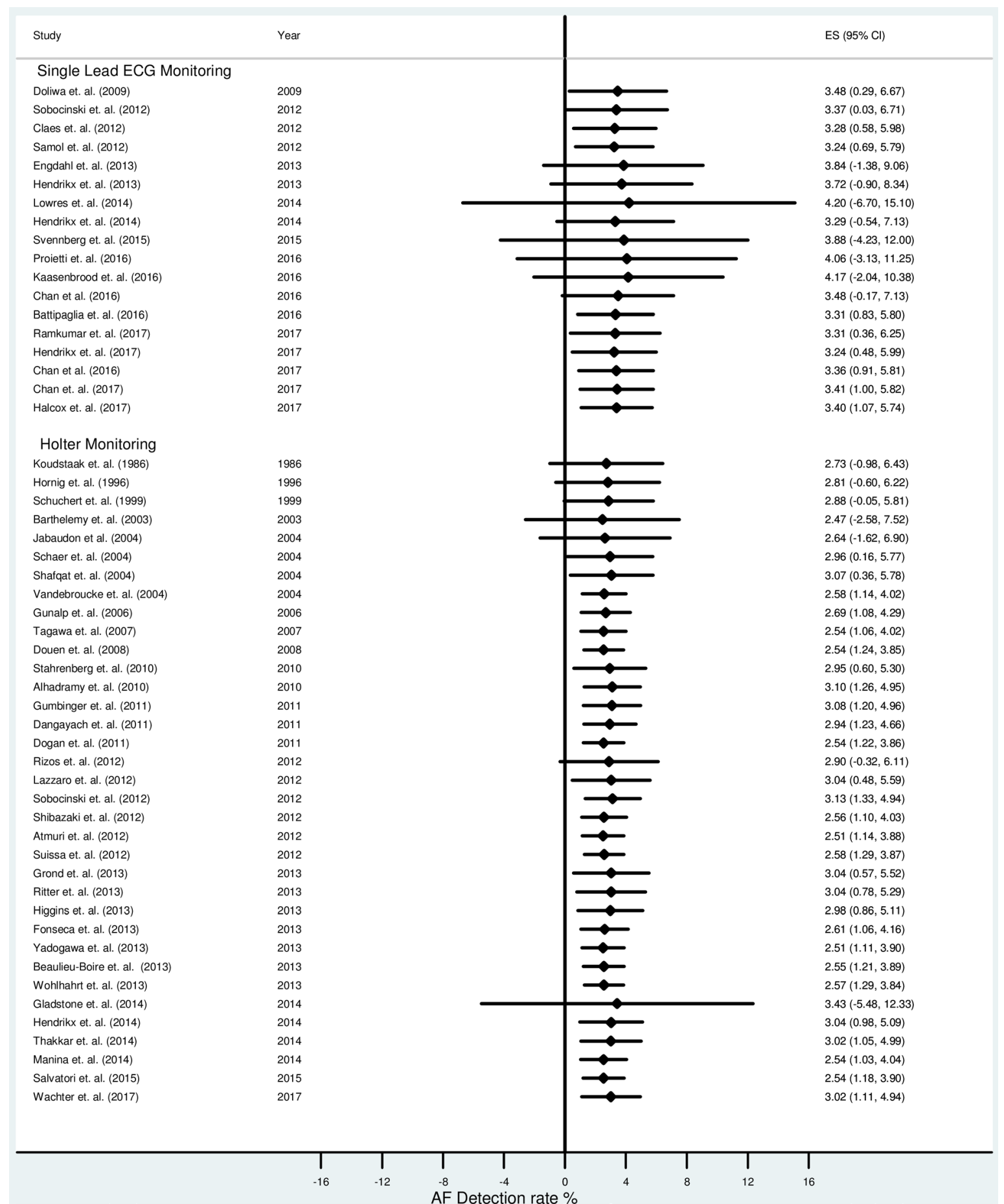

Figure 5 Cumulative meta-analysis showing minimal variation in atrial fibrillation (AF) detection over time using Holter and single-lead ECG devices. 
lifestyle intervention and aggressive risk factor modification following the early diagnosis of AF may be associated with positive LA remodelling and reduction of disease progression. Such a process may lead to additional health benefits, including reduction in cardiovascular risk and improvement in exercise capacity.

\section{AF screening and feasibility}

$\mathrm{AF}$ is a leading cause of stroke and heart failure in the community. As well as an association with increased all-cause mortality, it is associated with reduced quality of life. The availability of preventive therapies, including anticoagulation, has led to increasing recognition of the importance of AF screening for early diagnosis. However, AF screening shares the limitations of screening with other diagnostic tests. The screening tool must have high sensitivity, and needs to be inexpensive and cost-effective. We also need to minimise and have a method of addressing false positives. Current guidelines recommend opportunistic screening using pulse palpation and 12-lead ECG. ${ }^{11}$ In a previous systematic review, this was associated with a new AF detection rate of approximately $1 \% .^{5}$ Pulse palpation may be non-specific in patients with other irregular rhythms such as ventricular ectopy, and 12-lead ECG is only able to capture a single timepoint for screening. There are multiple other methods for AF detection. Continuous Holter monitoring is probably the most commonly used in clinical practice, especially in stroke cohorts. It has the potential advantage of assessing heart rhythm throughout the day and may be useful in detecting nocturnal subclinical AF. However, the disadvantages include the cost of Holter monitoring (especially for mass screening), the inconvenience of leads and electrodes (which may affect compliance) and typical limitation to 1-2 days of capture (as extended periods are more cumbersome and less cost-effective). Other event recorders are again expensive and limited to symptomatic patients. Extended period monitoring using implantable devices have shown promise in the cryptogenic stroke population (where many have been diagnosed with paroxysmal $\mathrm{AF}),{ }^{70}$ but they are invasive and not feasible for mass screening.

Portable single-lead ECG devices permit multiple $30-60 \mathrm{~s}$ recordings to be captured, and downloaded to a computer. These devices have several potential advantages over Holter monitoring. They are leadless and require finger contact (and are hence easy to use and acceptable to patients). They have a high degree of sensitivity for identifying AF. ${ }^{71-73}$ Most interface with a web-based cloud system where ECG rhythms can be wirelessly transferred to clinicians, allowing rapid analysis and diagnosis. The development of automated algorithms to detect $\mathrm{AF}$ is helpful for mass screening. In two small studies they have demonstrated superior AF detection compared with 24 hours Holter monitoring. ${ }^{66} 67$ Although screening using these portable devices are currently not in the latest AF guidelines, they may offer a feasible option for mass screening. Screening using these devices has been demonstrated to be cost-effective. $^{7475}$

We noted a moderate linear association between monitoring time and AF detection rate. Single timepoint screening for $30-60 \mathrm{~s}$ achieved an overall detection rate of approximately $1 \%$. This is no better than what has been reported using pulse palpation or 12-lead ECG, hence does not add any incremental benefit in screening programmes. ${ }^{5}$ Multiple intermittent recordings improve AF detection; we found that at least $19 \mathrm{~min}$ of total monitoring should be performed to achieve detection rates similar to 24 Holter monitoring.

The linear relationship between monitoring time and AF detection rate $\left(\mathrm{R}^{2}=0.80\right)$ and the reproduction of AF detection rates of 24 hours Holter monitoring with only $12 \mathrm{~min}$ of intermittent monitoring was possible in our study only after exclusion of an outlier. ${ }^{64}$ Despite the inclusion of elderly participants with at least one risk factor for $\mathrm{AF}$, the use of a validated single-lead ECG device and a prolonged monitoring period, that study had a lower AF detection rate $(3.8 \%)$ than the remaining studies, even using a shorter monitoring period..$^{5356}$ Relatively low rates of adherence (only approximately $25 \%$ completed $2 \times 30$ s ECG recordings every week for the full year of monitoring) may be a potential explanation for the lower AF detection rate noted. ${ }^{64}$

\section{Limitations}

There are several challenges inherent in this meta-analysis of studies investigating AF detection. The most important is the target screening population. Most studies did not report the CHADS or $\mathrm{CHA}_{2} \mathrm{DS}_{2}$-VASC score, a history of previous stroke or other comorbidities. Consequently, it was difficult to ascertain if the risk profiles of patients in these studies were equivalent. Most Holter monitoring studies were performed in the stroke population-which is likely a population with higher AF risk than many studies using portable ECG devices, which recruited mainly healthy participants or those with AF risk factors from the community. The significant heterogeneity among both Holter and portable ECG device studies make it difficult to perform direct comparisons between both groups. The type/duration of monitoring and type of device used will also influence the overall $\mathrm{AF}$ detection rate and varied significantly between studies. There are several possible confounders which may not have been taken into account. The validity of the linear regression analysis comparing detection time and rate may be limited due to the significant differences in study population, study design and AF definitions. However, despite these limitations, the analysis may provide some important inferences into AF screening. Multiple intermittent ECG recordings achieved a similar AF detection rate to 24 hours Holter monitoring. This may suggest that in a similar cohort of patients with the same comorbidities, 
single-lead intermittent monitoring may be superior for AF detection.

Compared with 24 hours continuous monitoring, single-lead portable ECG monitoring is more patient dependent. Good patient compliance is essential to obtain multiple readings across different timepoints which improves sensitivity. The analysis performed does not take into account patient compliance as this is difficult to assess and poorly reported across the individual studies. Most single-lead device manufacturers have proprietary automated AF detection algorithms, which were used for diagnosis. Not all of these algorithms have had rigorous testing and comparison to a reference standard. It is also difficult to distinguish AF from other supraventricular tachycardias using single-lead ECG devices as the $\mathrm{P}$ wave is often not readily discernible. The use of different automated algorithms makes AF definitions non-standardised and can potentially create issues with both overdiagnosis and underdiagnosis.

There are other limitations in this analysis. The efficacy of intermittent monitoring is critically dependent on AF burden and density. All studies varied in their monitoring period and strategy. The linear regression model used was able to determine a total intermittent monitoring time, which produced similar AF detection rates to 24 hours continuous monitoring. However, it is difficult to translate the total monitoring time into an effective monitoring strategy. For example, we are unable to determine from our analysis if $12 \times 60 \mathrm{~s}$ recordings over 12 consecutive days is different to $2 \times 60 \mathrm{~s}$ recordings daily for six consecutive days. The definitions of AF also vary between studies. Many are based on individual physician interpretation and criteria for diagnosis were not explicitly specified. The duration of AF varied from 10 to $30 \mathrm{~s}$ between studies, although a cut-off of $30 \mathrm{~s}$ was the most widely adopted practice.

\section{CONCLUSION}

Single-lead portable ECG devices may offer an efficient screening option for AF compared with 24 hours Holter monitoring. Total monitoring time is related to AF detection and a total of 19 min may achieve a similar detection rate to 24 hours Holter monitoring.

Contributors SR performed the literature search and analysis of individual studies. Involved in the statistical analysis, manuscript preparation and editing. THM is guarantor. Developed project idea/rationale. Involved in data analysis and manuscript preparation and editing. NN was involved in data and statistical analysis as well as manuscript preparation and editing. DDS performed the literature search and analysis of individual studies. Involved in the manuscript preparation and editing. DJP was involved in analysis of individual studies and statistical analysis. Involved in manuscript preparation and editing. JMK was involved in the project outline, data analysis, manuscript preparation and editing.

Funding This research received no specific grant from any funding agency in the public, commercial or not-for-profit sectors.

Disclaimer The sponsors had no role in the design and conduct of the study, in the collection, analysis and interpretation of the data and in the preparation, review or approval of the manuscript.
Competing interests SR receives equipment and software support from Semacare, a manufacturer of handheld ECG devices. Receives research scholarships from the Heart Foundation and Avant. THM receives equipment and software support from Semacare.

Patient consent Not requried.

Ethics approval Tasmanian Health and Medical Research Ethics Committee.

Provenance and peer review Not commissioned; externally peer reviewed.

Data sharing statement There are no remaining unpublished data.

Open access This is an open access article distributed in accordance with the Creative Commons Attribution Non Commercial (CC BY-NC 4.0) license, which permits others to distribute, remix, adapt, build upon this work non-commercially, and license their derivative works on different terms, provided the original work is properly cited, appropriate credit is given, any changes made indicated, and the use is non-commercial. See: http://creativecommons.org/licenses/by-nc/4.0/.

\section{REFERENCES}

1. Krahn AD, Manfreda J, Tate RB, et al. The natural history of atrial fibrillation: Incidence, risk factors, and prognosis in the manitoba follow-up study. Am J Med 1995;98:476-84.

2. Vidaillet H, Granada JF, Chyou P, et al. A population-based study of mortality among patients with atrial fibrillation or flutter. Am J Med 2002;113:365-70.

3. Kim MH, Johnston SS, Chu BC, et al. Estimation of total incremental health care costs in patients with atrial fibrillation in the United States. Circ Cardiovasc Qual Outcomes 2011;4:313-20.

4. Leyden JM, Kleinig TJ, Newbury J, et al. Adelaide stroke incidence study: declining stroke rates but many preventable cardioembolic strokes. Stroke 2013;44:1226-31.

5. Lowres N, Neubeck L, Redfern J, et al. Screening to identify unknown atrial fibrillation. A systematic review. Thromb Haemost 2013;110:213-22.

6. Watanabe $\mathrm{H}$, Tanabe N, Watanabe T, et al. Metabolic syndrome and risk of development of atrial fibrillation. Circulation 2008; 117:1255-60.

7. Ball J, Thompson DR, Ski CF, et al. Estimating the current and future prevalence of atrial fibrillation in the Australian adult population. Med J Aust 2015;202:32-5.

8. Dagres N, Anastasiou-Nana M. Atrial Fibrillation and Obesity. J Am Coll Cardiol 2010;55:2328-9.

9. Sposato LA, Cipriano LE, Saposnik G, et al. Diagnosis of atrial fibrillation after stroke and transient ischaemic attack: a systematic review and meta-analysis. Lancet Neurol 2015;14:377-87.

10. Pathak RK, Middeldorp ME, Lau DH, et al. Aggressive risk factor reduction study for atrial fibrillation and implications for the outcome of ablation: the ARREST-AF cohort study. J Am Coll Cardiol 2014;64:2222-31.

11. Kirchhof P, Benussi S, Kotecha D, et al. 2016 ESC Guidelines for the management of atrial fibrillation developed in collaboration with EACTS. Eur Heart J 2016;37:2893-962.

12. Martinez C, Katholing A, Freedman SB. Adverse prognosis of incidentally detected ambulatory atrial fibrillation. A cohort study. Thromb Haemost 2014;112:276-86.

13. Lau J, Lowres N, Neubeck L, et al. Performance of an automated iPhone ECG algorithm to diagnose atrial fibrillation in a community AF screening program (SEARCH-AF). Heart, Lung and Circulation 2013;22:S205.

14. Doliwa PS, Frykman V, Rosenqvist M. Short-term ECG for out of hospital detection of silent atrial fibrillation episodes. Scand Cardiovasc J 2009;43:163-8.

15. Chan PH, Wong CK, Poh YC, et al. Diagnostic performance of a smartphone-based photoplethysmographic application for atrial fibrillation screening in a primary care setting. J Am Heart Assoc 2016;5:e003428.

16. Moher D, Liberati A, Tetzlaff J, et al. Preferred reporting items for systematic reviews and meta-analyses: the PRISMA statement. PLoS Med 2009;6:e1000097.

17. Downs SH, Black N. The feasibility of creating a checklist for the assessment of the methodological quality both of randomised and non-randomised studies of health care interventions. J Epidemiol Community Health 1998;52:377-84.

18. Gladstone DJ, Spring M, Dorian $P$, et al. Atrial fibrillation in patients with cryptogenic stroke. N Engl J Med 2014;370:2467-77.

19. Barthélémy JC, Féasson-Gérard S, Garnier P, et al. Automatic cardiac event recorders reveal paroxysmal atrial fibrillation after 
unexplained strokes or transient ischemic attacks. Ann Noninvasive Electrocardiol 2003;8:194-9.

20. Jabaudon D, Sztajzel J, Sievert K, et al. Usefulness of ambulatory 7-day ECG monitoring for the detection of atrial fibrillation and flutter after acute stroke and transient ischemic attack. Stroke 2004;35:1647-51.

21. Koudstaal PJ, van Gijn J, Klootwijk AP, et al. Holter monitoring in patients with transient and focal ischemic attacks of the brain. Stroke 1986;17:192-5

22. Hornig CR, Haberbosch W, Lammers C, et al. Specific cardiological evaluation after focal cerebral ischemia. Acta Neurol Scand 1996:93:297-302.

23. Rizos T, Güntner J, Jenetzky E, et al. Continuous stroke unit electrocardiographic monitoring versus 24-hour Holter electrocardiography for detection of paroxysmal atrial fibrillation after stroke. Stroke 2012;43:2689-94.

24. Schuchert A, Behrens G, Meinertz T. Impact of long-term ECG recording on the detection of paroxysmal atrial fibrillation in patients after an acute ischemic stroke. Pacing Clin Electrophysiol 1999;22:1082-4

25. Schaer B, Sticherling C, Lyrer P, et al. Cardiological diagnostic workup in stroke patients--a comprehensive study of test results and therapeutic implications. Eur J Neurol 2009;16:268-73.

26. Schaer BA, Zellweger MJ, Cron TA, et al. Value of routine holter monitoring for the detection of paroxysmal atrial fibrillation in patients with cerebral ischemic events. Stroke 2004;35:68e-70.

27. Shafqat S, Kelly PJ, Furie KL. Holter monitoring in the diagnosis of stroke mechanism. Intern Med J 2004;34:305-9.

28. Lazzaro MA, Krishnan K, Prabhakaran S. Detection of atrial fibrillation with concurrent holter monitoring and continuous cardiac telemetry following ischemic stroke and transient ischemic attack. J Stroke Cerebrovasc Dis 2012;21:89-93.

29. Grond M, Jauss M, Hamann G, et al. Improved detection of silent atrial fibrillation using 72-hour Holter ECG in patients with ischemic stroke. Stroke 2013;44:3357-64.

30. Stahrenberg R, Weber-Krüger M, Seegers J, et al. Enhanced detection of paroxysmal atrial fibrillation by early and prolonged continuous holter monitoring in patients with cerebral ischemia presenting in sinus rhythm. Stroke 2010;41:2884-8.

31. Ritter MA, Kochhäuser S, Duning T, et al, 2013. Stroke Occult atrial fibrillation in cryptogenic stroke: detection by 7 -day electrocardiogram versus implantable cardiac monitors; 44:1449-52.

32. Higgins P, MacFarlane PW, Dawson J, et al, 2013. Stroke Noninvasive cardiac event monitoring to detect atrial fibrillation after ischemic stroke: a randomized, controlled trial;44:2525-31.

33. Thakkar S, Bagarhatta R. Detection of paroxysmal atrial fibrillation or flutter in patients with acute ischemic stroke or transient ischemic attack by holter monitoring. Indian Heart J 2014;66:188-92.

34. Wachter R, Gröschel K, Gelbrich G, et al. Holter-electrocardiogrammonitoring in patients with acute ischaemic stroke (Find-AF an open-label $\quad$ controlled trial. Lancet Neurol 2017;16:282-90.

35. Gumbinger C, Krumsdorf U, Veltkamp R, et al, 2012. Eur J Neurol Continuous monitoring versus HOLTER ECG for detection of atrial fibrillation in patients with stroke;19:253-7.

36. Alhadramy O, Jeerakathil TJ, Majumdar SR, et al. Prevalence and predictors of paroxysmal atrial fibrillation on Holter monitor in patients with stroke or transient ischemic attack. Stroke 2010;41:2596-600.

37. Dangayach NS, Kane K, Moonis M. Paroxysmal atrial fibrillation in cryptogenic stroke. Ther Clin Risk Manag 2011;7:33-7.

38. Gunalp M, Atalar E, Coskun F, et al. Holter monitoring for 24 hours in patients with thromboembolic stroke and sinus rhythm diagnosed in the emergency department. Adv Ther 2006;23:854-60.

39. Fonseca AC, Brito D, Pinho e Melo T, et al. N-terminal pro-brain natriuretic peptide shows diagnostic accuracy for detecting atrial fibrillation in cryptogenic stroke patients. Int J Stroke 2014;9:419-25.

40. Manina G, Agnelli G, Becattini C, et al, 2014. Intern Emerg Med 96 hours ECG monitoring for patients with ischemic cryptogenic stroke or transient ischaemic attack;9:65-7.

41. Tagawa M, Takeuchi S, Chinushi M, et al. Evaluating patients with acute ischemic stroke with special reference to newly developed atrial fibrillation in cerebral embolism. Pacing Clin Electrophysiol 2007;30:1121-8

42. Shibazaki K, Kimura K, Fujii S, et al. Brain natriuretic peptide levels as a predictor for new atrial fibrillation during hospitalization in patients with acute ischemic stroke. Am J Cardiol 2012;109:1303-7.

43. Vandenbroucke E, Thijs VN. Diagnostic and therapeutic impact of ambulatory electrocardiography in acute stroke. Acta Neurol Belg 2004;104:27-31.
44. Yodogawa K, Seino Y, Ohara T, et al. Prediction of atrial fibrillation after ischemic stroke using P-wave signal averaged electrocardiography. J Cardiol 2013;61:49-52.

45. Atmuri $\mathrm{K}$, Hughes $\mathrm{A}$, Coles $\mathrm{D}$, et al. The role of cardiac disease parameters in predicting the results of Holter monitoring in patients with acute ischaemic stroke. J Clin Neurosci 2012;19:965-8.

46. Salvatori V, Becattini C, Laureti S, et al. Holter monitoring to detect silent atrial fibrillation in high-risk subjects: The perugia general practitioner study. Intern Emerg Med 2015;10:595-601.

47. Beaulieu-Boire I, Leblanc N, Berger L, et al. Troponin elevation predicts atrial fibrillation in patients with stroke or transient ischemic attack. J Stroke Cerebrovasc Dis 2013;22:978-83.

48. Dogan U, Dogan EA, Tekinalp M, et al. P-wave dispersion for predicting paroxysmal atrial fibrillation in acute ischemic stroke. Int $\mathrm{J}$ Med Sci 2012;9:108-14.

49. Douen AG, Pageau N, Medic S. Serial electrocardiographic assessments significantly improve detection of atrial fibrillation 2.6fold in patients with acute stroke. Stroke 2008;39:480-2.

50. Suissa L, Lachaud S, Mahagne MH, et al. Optimal timing and duration of continuous electrocardiographic monitoring for detecting atrial fibrillation in stroke patients. $J$ Stroke Cerebrovasc Dis 2013;22:991-5

51. Wohlfahrt J, Stahrenberg R, Weber-Krüger M, et al, 2014. Eur J Neurol Clinical predictors to identify paroxysmal atrial fibrillation after ischaemic stroke;21:21-7.

52. Lowres N, Neubeck L, Salkeld G, et al. Feasibility and costeffectiveness of stroke prevention through community screening for atrial fibrillation using iPhone ECG in pharmacies. The SEARCH-AF study. Thromb Haemost 2014;111:1167-76.

53. Svennberg E, Engdahl J, Al-Khalili F, et al. Mass screening for untreated atrial fibrillation: the STROKESTOP study. Circulation 2015;131:2176-84

54. Proietti M, Mairesse GH, Goethals $\mathrm{P}$, et al. A population screening programme for atrial fibrillation: a report from the Belgian Heart Rhythm Week screening programme. Europace 2016;18:euw069-86.

55. Kaasenbrood F, Hollander M, Rutten FH, et al. Yield of screening for atrial fibrillation in primary care with a hand-held, single-lead electrocardiogram device during influenza vaccination. Europace 2016;18:1514-20.

56. Engdahl J, Andersson L, Mirskaya M, et al. Stepwise screening of atrial fibrillation in a 75-year-old populationclinical perspective. Circulation 2013;127:930-7.

57. Hendrikx T, Hörnsten R, Rosenqvist M, et al. Screening for atrial fibrillation with baseline and intermittent ECG recording in an out-ofhospital population. BMC Cardiovasc Disord 2013;13:41.

58. Hendrikx T, Sundqvist M, Sandström $\mathrm{H}$, et al. Atrial fibrillation among patients under investigation for suspected obstructive sleep apnea. PLoS One 2017;12:e0171575

59. Chan NY, Choy CC. Screening for atrial fibrillation in 13122 Hong Kong citizens with smartphone electrocardiogram. Heart 2017;103:24-31.

60. Ramkumar S, Yang H, Wang $\mathrm{Y}$, et al. The role of left atrial and ventricular function in prediction of atrial fibrillation: P2-19. Journal of the American Society of Echocardiography 2017;30:B70.

61. Claes N, Goethals M, Goethals P, et al. Screening for atrial fibrillation (AF) in Belgium: a multicentre trial. European Journal of Cardiovascular Prevention and Rehabilitation 2011:1:S30.

62. Samol A, Masin M, Gellner R, et al. Prevalence of unknown atrial fibrillation in patients with risk factors. Europace 2013;15:657-62.

63. Battipaglia I, Gilbert K, Hogarth AJ, et al. Screening for atrial fibrillation in the community using a novel ECG recorder. J Atr Fibrillation 2016:9:29-31.

64. Halcox JPJ, Wareham K, Cardew A, et al. Assessment of remote heart rhythm sampling using the alivecor heart monitor to screen for atrial fibrillation: the REHEARSE-AF study. Circulation 2017;136:1784-94. 117.030583

65. Chan NY, Siu CW, Choy CC, et al. Effectiveness of community atrial fibrillation screening in over 10,000 citizens using smartphone electrocardiogram- The AFinder program. ESC Congress. Barcelona, 2017.

66. Doliwa Sobocinski P, Anggårdh Rooth E, Frykman Kull V, et al. Improved screening for silent atrial fibrillation after ischaemic stroke. Europace 2012;14:1112-6.

67. Hendrikx T, Rosenqvist M, Wester P, et al. Intermittent short ECG recording is more effective than 24-hour Holter ECG in detection of arrhythmias. BMC Cardiovasc Disord 2014;14:41.

68. Stewart S, Murphy NF, Murphy N, et al. Cost of an emerging epidemic: an economic analysis of atrial fibrillation in the UK. Heart 2004;90:286-92

69. Healey JS, Connolly SJ, Gold MR, et al. Subclinical atrial fibrillation and the risk of stroke. N Engl J Med 2012;366:120-9. 
70. Sanna T, Diener HC, Passman RS, et al. Cryptogenic stroke and underlying atrial fibrillation. N Engl J Med 2014;370:2478-86.

71. Desteghe L, Raymaekers Z, Lutin M, et al. Performance of handheld electrocardiogram devices to detect atrial fibrillation in a cardiology and geriatric ward setting. Europace 2017;19. euw025.

72. Williams J, Pearce K, Benett I, et al. The effectiveness of a mobile ECG device in identifying AF: sensitivity, specificity and predictive value. British Journal of Cardiology 2015;22.
73. Ben Freedman S, Lowres N. Asymptomatic atrial fibrillation: the case for screening to prevent stroke. JAMA 2015;314:1911-2.

74. Aronsson M, Svennberg E, Rosenqvist M, et al. Cost-effectiveness of mass screening for untreated atrial fibrillation using intermittent ECG recording. Europace 2015;17:1023-9.

75. Jacobs MS, Kaasenbrood F, Postma MJ, et al. Cost-effectiveness of screening for atrial fibrillation in primary care with a handheld, single-lead electrocardiogram device in the Netherlands. Europace 2018;20:euw285. euw285. 